\title{
Distribution of laminin, fibronectin, and interstitial collagen type III in soft tissue tumours
}

\author{
AJ D' ARDENNE, P KIRKPATRICK, BC SYKES \\ From the Department of Pathology, John Radcliffe Hospital, Headington, Oxford
}

SUMMARY The distributions of laminin, fibronectin, and interstitial collagen type III have been investigated in a series of 60 soft tissue tumours by immunochemistry. Positive laminin staining was seen in sites predicted by the distribution of ultrastructurally visible basal lamina. Pericellular laminin was present in all benign tumours of Schwann cell and smooth muscle origin examined, in the two malignant Schwannomas examined, and in six of 13 leiomyosarcomas. It was also evident around nests of cells in an alveolar soft part sarcoma and around malignant endothelial cells in an angiosarcoma. In fibroblastic and fibrohistiocytic tumours it was found only in blood vessel walls. The results of laminin staining led to revision of the original histopathological diagnosis in seven of the 60 cases studied. Fibronectin was abundant in the stroma of most neoplasms, both benign and malignant. It was also found in a distribution parallel to that of laminin. In some tumours this was clearly distinguishable from the distribution of interstitial collagen. Intracellular fibronectin was shown consistently only in mast cell granules. Its demonstration in synovial cells, fibroblasts, and histiocytes was more variable. Interstitial collagen type III had the most irregular distribution of the three proteins. It was as plentiful in tumours of smooth muscle origin as in tumours of fibroblastic origin, but was scanty in fibrous histiocytomas. Its distribution appeared similar to that of laminin and fibronectin in leiomyomas, but differed from these two proteins in Schwann cell tumours and other neoplasms. In one leiomyosarcoma fibronectin, laminin, and type III collagen appeared to be lost concomitantly from tumour cell peripheries.

Extracellular matrices of soft tissues can be divided by ultrastructural morphology into two principal components: (1) amorphous basal lamina adjacent to cells and (2) interstitial connective tissue containing fibrillar and cross striated collagen.' Basal lamina is present around smooth and striated muscle cells and Schwann cells but is absent from the periphery of fibroblasts. It is also found at epithelial and endothelial cell bases. Its principal constituents include the non-collagenous glycoprotein laminin ${ }^{23}$ collagen type IV, ${ }^{4}$ and proteoglycans. ${ }^{56}$ Interstitial connective tissue contains proteoglycans ${ }^{7}$ and collagens type I and III. ${ }^{8}$ Fibronectin is probably present in both basal lamina and interstitial connective tissue, particularly in association with cell surfaces, ${ }^{910}$ although its location in basal lamina has been questioned." ${ }^{11}$ Both fibronectin and laminin promote cellular adhesion in tissue culture, ${ }^{8}$ but unlike laminin, fibronectin is associated with fibro-

Accepted for publication 8 May 1984 blasts and macrophages as well as with cells possessing a basal lamina in vivo. ${ }^{12}$ It is also present in a soluble form in extracellular body fluids.

Interest in fibronectin was intensified by the finding that in vitro it is sometimes, although not invariably, lost from the surfaces of cells on malignant transformation. ${ }^{13}$ It may be lost concomitantly with laminin and heparan sulphate proteoglycan..$^{14}$ Immunohistochemical studies of the distributions of these proteins in human epithelial neoplasms have shown that laminin may be found in varying quantities around islands of invasive carcinoma or may be completely absent. ${ }^{1516}$ This appears to correspond with the distribution of ultrastructurally visible basal lamina, ${ }^{17}$ although a direct correlation has yet to be made. Stromal fibronectin is considerably increased in most carcinomas along with interstitial collagen. ${ }^{18} 19$ It is often impossible to distinguish between stromal and cell surface fibronectin by light microscopy, but investigation of a few tumours where stromal fibronectin is minimal has indicated that like laminin it is sometimes but not always 
absent from carcinoma cell surfaces. ${ }^{19}$

Previous investigators of soft tissue tumours have reached differing conclusions regarding the relation of fibronectin to malignant mesenchymal cells in vivo, ${ }^{1820}$ although all have shown that as in carcinomas stromal fibronectin is usually plentiful. Du Boulay found intracytoplasmic staining for fibronectin in fibrous histiocytic and synovial cells and suggested that this may be of diagnostic value.21 Another study has indicated that laminin staining may be useful as a marker for tumours of Schwann cell or smooth muscle origin..$^{22}$ In the present investigation the distributions of fibronectin, laminin, and type III collagen have been compared in a series of 60 soft tissue tumours. The intention was to define the relations of matrical constituents in these neoplasms, both with each other and with tumour cells, and to assess the potential value of such staining in diagnostic histopathology.

\section{Material and methods}

Material was examined from 24 benign and 36 malignant soft tissue tumours. The benign tumours included leiomyomas from skin, rectum, uterus, and larynx; four benign fibrous histiocytomas or dermatofibromas; four giant cell tumours of tendon sheath; six neurofibromas; and six schwannomas. Details of the malignant tumours are summarised in Table 1. Degree of malignancy was graded I-III on the basis of cellularity, cellular pleomorphism, mitotic activity, and necrosis. ${ }^{23}$ The tissue had been fixed in $10 \%$ formol saline and embedded in paraffin wax after routine processing. The storage period of paraffin blocks used for investigation ranged from two days to 10 years. In a few cases fresh tissue was also available. This was frozen in liquid nitrogen after removal of small pieces for fixation in glutaraldehyde and processing for electron microscopy.

Paraffin sections were cut at $4 \mu \mathrm{m}$ and stained by the indirect immunoperoxidase procedure after protease digestion as previously described. ${ }^{19} 2425$ Dewaxed sections were incubated in $0.05 \%$ protease type VII (Sigma Cat No P5255) in phosphate buffered saline (PBS), $\mathrm{pH} 7 \cdot 3$, for $20 \mathrm{~min}$ at $37^{\circ} \mathrm{C}$. Digestion was terminated in cold running tap water. After further washes in PBS, sections were exposed to normal swine serum diluted $1 / 5$ with PBS for $10 \mathrm{~min}$ before proceeding with the routine indirect immunoperoxidase technique. Sections of frozen tissue were stained by indirect immunofluorescence without prior digestion. Control sections in both procedures were incubated with non-immune rabbit or goat IgG or with PBS in place of the first antibody.

The antibody to human type III collagen was raised in a goat; its preparation and purification have been described previously. ${ }^{14}$ Rabbit antihuman fibronectin antiserum and peroxidase conjugated antirabbit IgG were obtained from Dakopatts, Mercia Brocades Ltd. Antibodies to laminin (produced by immunisation of rabbits with laminin purified from mouse EHS sarcoma) were obtained from Bethesda Research Laboratories (BRL 6265 LA). These gave positive staining of human basement membranes in all normal tissues tested. No other connective tissue elements were stained. Fluorescein isothiocyanate and peroxidase conjugated anti-

Table 1 Details of malignant tumours studied

\begin{tabular}{|c|c|c|c|c|}
\hline Diagnosis & Case nos & Tumour site & Tumour grade gu $^{23}$ & $\begin{array}{l}\text { Tumour size } \\
\text { (maximum diameter in } \mathrm{cm} \text { ) }\end{array}$ \\
\hline \multirow[t]{7}{*}{ Leiomyosarcoma } & $1-4$ & Ileum & II, III, II, I & $6,8,11,17$ \\
\hline & $5,6,7$ & Skin & I, II, I & $1 \cdot 5,6, .1$ \\
\hline & & Metastasis in subcutaneous fat & III & 1 \\
\hline & & Broad ligament & I & 23 \\
\hline & 10,11 & Retroperitoneum & III, II & 15,23 \\
\hline & 12 & Abdomen & & Trucut biopsy \\
\hline & 13 & Scrotum & II & 10 \\
\hline \multirow[t]{2}{*}{ Malignant schwannoma } & 14 & Skin & II & $3 \cdot 5$ \\
\hline & & Mediastinum & I & 12 \\
\hline \multirow[t]{4}{*}{ Fibrosarcoma } & 16,17 & Thigh & II, III & 5,7 \\
\hline & 18 & Axilla & III & Trucut biopsy \\
\hline & 19 & Anterior abdominal wall & I & $1 \cdot 5$ \\
\hline & 20 & Face & II & 9 \\
\hline \multirow[t]{3}{*}{ Dermatofibrosarcoma protuberans } & $21-23$ & Scalp & I & $2 \cdot 5,1 \cdot 5,6$ \\
\hline & 24 & Leg & I & 2 \\
\hline & & Shoulder & I & $\overline{1}$ \\
\hline \multirow[t]{3}{*}{ Malignant fibrous histiocytoma } & 26,27 & Scalp & II & $2,2 \cdot 5$ \\
\hline & 28 & Shoulder & III & 2 \\
\hline & 29 & Breast & II & $1 \cdot 5$ \\
\hline Synovial sarcoma & 30 & Thigh & II & 3 \\
\hline Alveolar soft part sarcoma & 31 & Brachialis muscle & II & 4 \\
\hline Angiosarcoma & 32 & Face & I-II & Multiple nodules \\
\hline Sarcoma (? type) & $33-36$ & Neck, abdomen & III & Multiple metastatic nodules \\
\hline
\end{tabular}


Table 2 Summary of results in benign tumours

\begin{tabular}{llll}
\hline Diagnosis & Fibronectin & Laminin & $\begin{array}{c}\text { Type III } \\
\text { collagen }\end{array}$ \\
\hline $\begin{array}{l}\text { Leiomyoma } \\
\text { Benign fibrous }\end{array}$ & +++ & +++ & +++ \\
$\begin{array}{l}\text { histiocytoma } \\
\text { Giant cell tumour of } \\
\text { tendon sheath }\end{array}$ & +++ & - & + \\
$\begin{array}{l}\text { Neurofibroma } \\
\text { Schwannoma }\end{array}$ & +++ & - & +++ \\
\end{tabular}

+ to $+++=$ amount of positive staining present by subjective assessment.

- = staining confined to vascular walls.

bodies against goat and rabbit IgG were obtained from Miles Yeda Limited. All antisera were diluted $1 / 30$ to $1 / 50$ in PBS, $\mathrm{pH} 7 \cdot 3$, for use.

\section{Results}

The results are summarised in Tables 2 and 3. Quantity rather than intensity of positive staining was subjectively graded on a scale - to +++ . Where staining was confined to vascular walls the result was recorded as negative. Each section of tissue had an inbuilt positive control in that each contained normal connective tissue elements expected to stain positively with these antibodies. In particular, staining for laminin and fibronectin was present in all vascular basement membranes. Controls substituting non-immune rabbit or goat IgG or PBS for the primary antibody were all negative.

\section{MAST CELLS}

Many of the soft tissue tumours examined contained numerous mast cells. These all showed a striking and strongly positive staining for fibronectin within their granules (Fig. 1). There was no evidence of mast cell staining in negative controls or in preparations stained for laminin or type III collagen.

\section{BENIGN TUMOURS}

Each type of benign tumour had a characteristic staining pattern for fibronectin, laminin, and type III collagen (Table 2). Leiomyomas stained in a manner virtually identical to that of normal smooth muscle, with all three proteins distributed around smooth muscle cells (Fig. 1). In benign fibrous histiocytomas, fibronectin was abundant in the stroma and sometimes detected in histiocytes, but type III collagen appeared scanty relative to that present in surrounding dermal connective tissue. Laminin was absent except in capillary walls, which were frequently numerous and conspicuous. In giant cell tumours of tendon sheath, intracytoplasmic fibronectin was seen in mononuclear cells but not in the giant cells (Fig. 2). It was also plentiful in the stroma. No laminin was present except in capillary walls. Type III collagen was found in stromal bundles. In neurofibromas and schwannomas both fibronectin and laminin had a strongly positive staining pattern with a distinctive and apparently identical distribution around Schwann cells (Fig. 3). Type III collagen was more irregularly dispersed, although plentiful in schwannoma capsules.

In three of the 24 benign tumours examined, staining for matrical proteins, in particular laminin, led to revision of the original diagnosis. In two instances fibroblastic lesions had been misdiagnosed as neurofibromas and in one instance a dermal neurofibroma had been labelled a fibrous histiocytoma.

\section{MALIGNANT TUMOURS (Table 3) \\ Leiomyosarcomas}

Five of thirteen leiomyosarcomas (cases 5, 7, 9, 10, and 13) showed pericellular staining for fibronectin, laminin, and type III collagen throughout the tumour as in benign smooth muscle lesions. In three of these cases $(5,7$, and 10$)$ this staining pattern resulted in revision of the original diagnosis.

Case 5 was a $1.5 \mathrm{~cm}$ diameter non-encapsulated

Table 3 Summary of results in malignant tumours

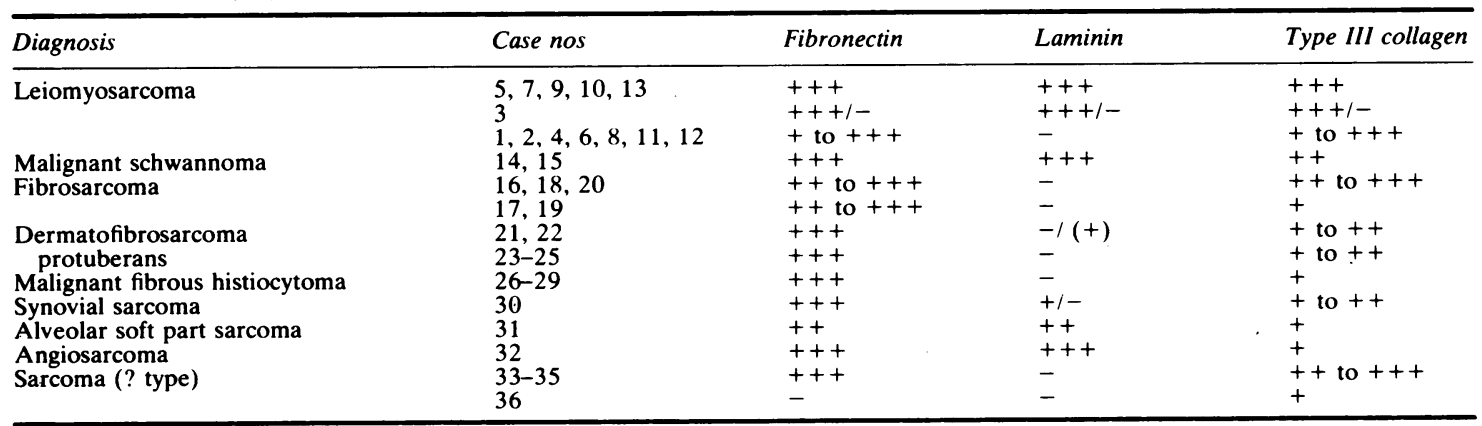




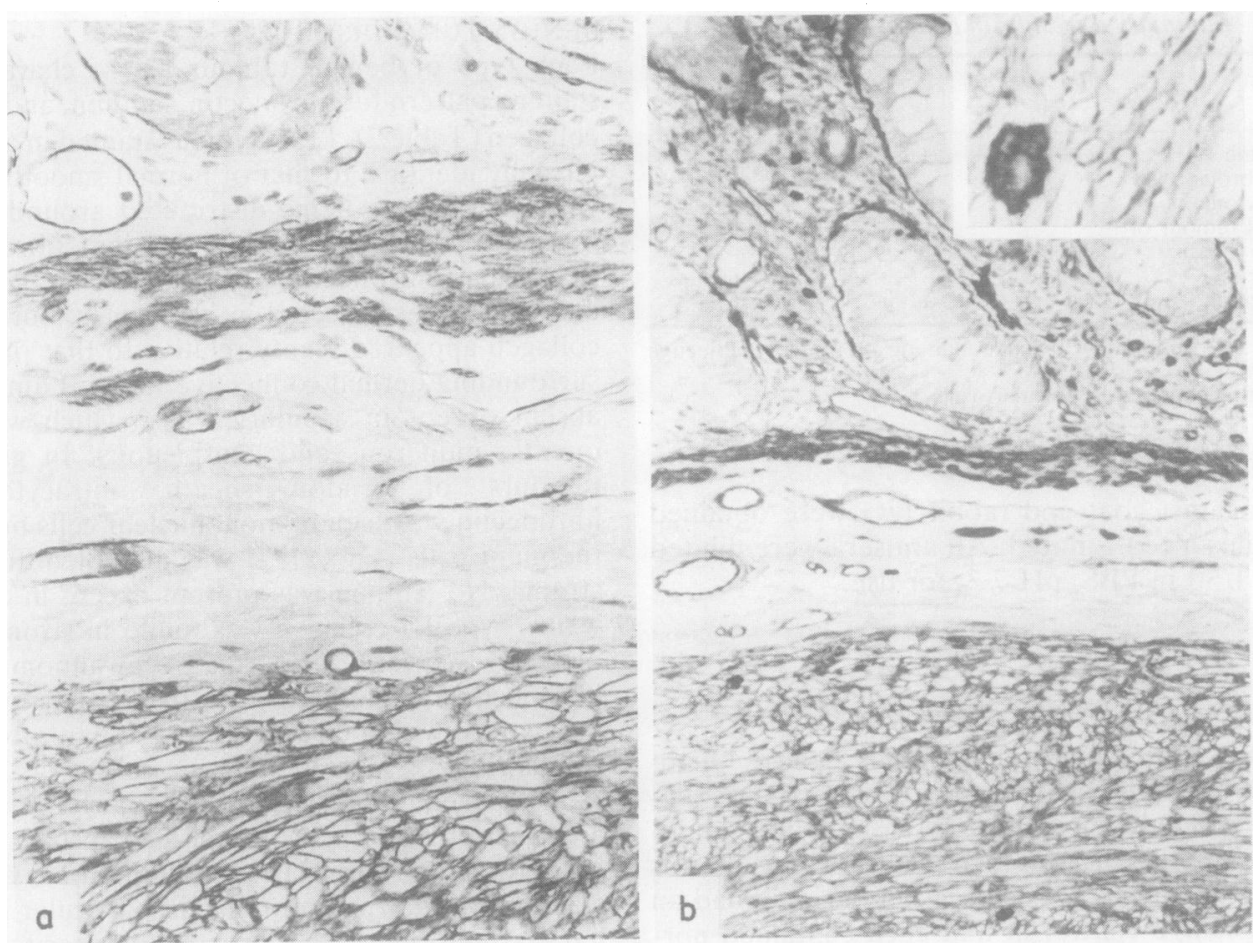

Fig. 1 Leiomyoma of rectum stained for laminin (a) and fibronectin ( $b$ and inset). Both proteins are present around smooth muscle cells of muscularis mucosa and tumour and in epithelial and vascular basement membranes. Intracellular fibronectin is seen in mast cells (inset). Indirect immunoperoxidase/haematoxylin. $\times 300(a) ; \times 150(b) ; \times 720$ (inset).

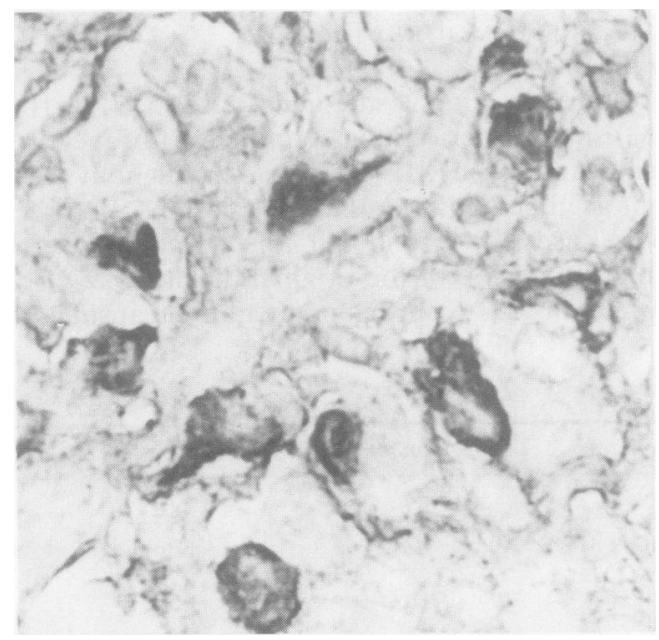

Fig. 2 Giant cell tumour of tendon sheath stained for fibronectin. Immunoperoxidase/haematoxylin. $\times 600$.

tumour from skin of the back with irregular bundles of spindle shaped cells thought to have a focal storiform pattern. Mitotic index was 10/10 high power fields. It was originally diagnosed as a dermatofibrosarcoma protuberans, but the presence of pericellular laminin rendered this unlikely and subsequent electron microscopy showed cells of smooth muscle origin.

Case 7 was a recurrent $1 \mathrm{~cm}$ diameter subcutaneous nodule from the calf of an 82 year old woman. It had been diagnosed as a fibrosarcoma. After finding pericellular laminin, tissue was retrieved from a paraffin block and processed for electron microscopy. Morphology was not good, but intracytoplasmic filaments with focal densities were readily discerned as well as some basal lamina, indicating that this was a leiomyosarcoma. ${ }^{26}$

Case 10 was a retroperitoneal mass $15 \mathrm{~cm}$ diameter in a 31 year old woman. There was extensive necrosis within this tumour together with inflammatory cells and multinucleate giant cells. Conspicuous nuclear and cellular pleomorphism were present and mitotic rate was high. The tumour was originally thought to be a malignant fibrous histiocytoma, but immunohistochemistry showed abundant pericellular laminin, fibronectin, and type III collagen throughout. Electron microscopy was performed on 

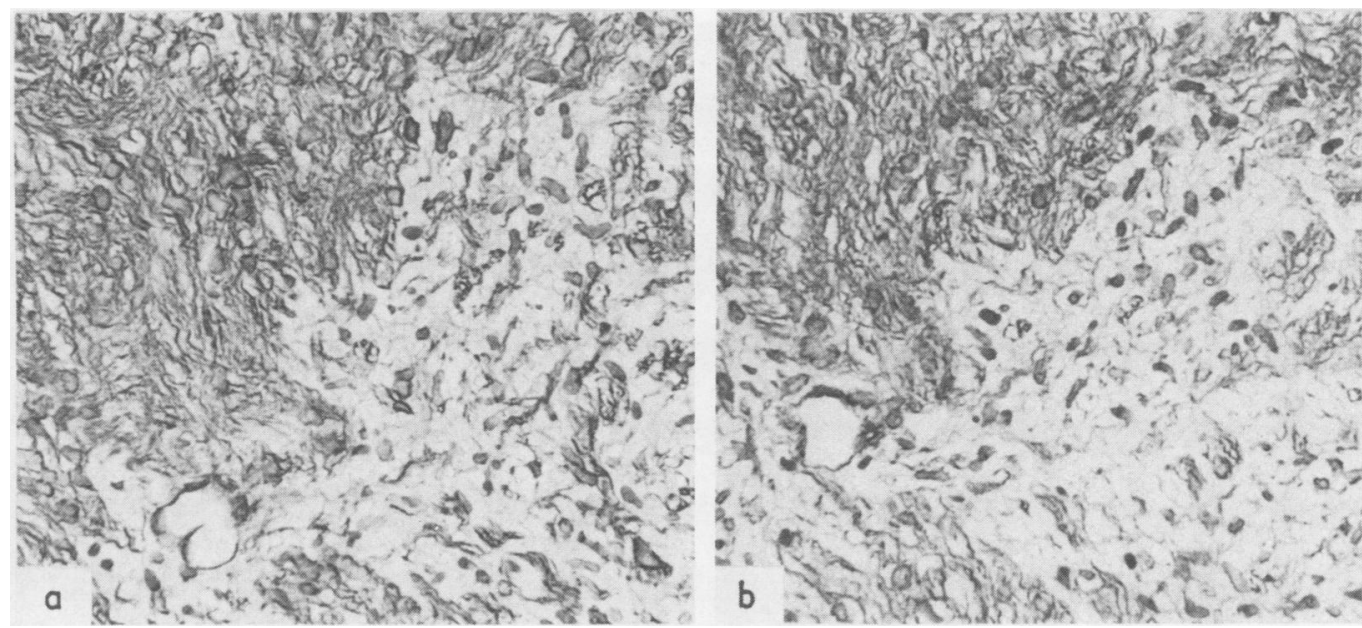

Fig. 3 Schwannoma stained for laminin (a) and fibronectin (b) showing codistribution of these proteins around Schwann cells. Immunoperoxidase/haematoxylin. $\times 360$.

tissue retrieved from a paraffin block and was compatible with a diagnosis of leiomyosarcoma.

One leiomyosarcoma from the ileum (Case 3) was of particular interest because pericellular laminin, fibronectin, and type III collagen were present in only one part, of the tumour. In other areas they were either absent or present in a more irregular distribution. Staining of consecutive serial sections for these three proteins indicated that the regions of pericellular positivity were coincident (Fig. 4). Both fibronectin and type III collagen were present in moderate amounts in a metastasis from this tumour, but were irregularly dispersed and laminin was only barely detectable around a few cells adjacent tc blood vessels.

In the remaining seven cases diagnosed as leiomyosarcomas, stromal fibronectin and type III collagen were both usually moderately plentiful, but distinct pericellular laminin was absent.

\section{Malignant schwannomas}

Two malignant neural tumours were examined, one from skin and one from mediastinum. Both showed strong positive pericellular staining for laminin and fibronectin. Type III collagen was more irregularly distributed. These tumours were both considered low to moderate grade on standard morphological criteria. In the skin tumour the presence of abundant laminin resulted in revision of the original diagnosis of fibrosarcoma. This diagnosis was supported by electron microscopy.

\section{Fibrosarcomas}

The remaining five tumours diagnosed as fibrosarcoma contained moderate to abundant stromal fibronectin and no pericellular laminin. In three stromal type III collagen was also plentiful, but in cases 17 and 19 it was present in smaller amounts.

\section{Dermatofibrosarcoma protuberans}

All these tumours showed diffuse fibrillar staining for fibronectin throughout the stroma, focally reproducing their characteristic storiform pattern. The distribution appeared predominantly pericellular, although there was a suggestion of cytoplasmic staining in a few areas. The slender nature of the tumour cells sometimes made it difficult to distinguish between the two. Laminin was conspicuous in blood vessel walls but mostly absent from stroma. In two tumours (21 and 22) from the scalp there was weak and focal pericellular laminin positivity. Since it was difficult to be certain whether this represented a genuine reaction it was recorded as $-/(+)$. The strongly positive pericellular laminin staining characteristic of neural and smooth muscle tumours was not evident. Type III collagen was present as fine fibres in stroma but was much less conspicuous than fibronectin.

\section{Malignant fibrous histiocytomas}

These tumours all had abundant stromal fibronectin, but only one (29) had moderately strong cytoplasmic positivity in mononuclear fibrohistiocytic cells (Fig. 5). Multinucleate cells were negative for fibronectin in all four tumours examined. Staining for laminin was negative except in blood vessel walls. Type III collagen was scanty but present in delicate fibres in stroma.

Synovial sarcoma

This was a tumour consisting predominantly of spin- 


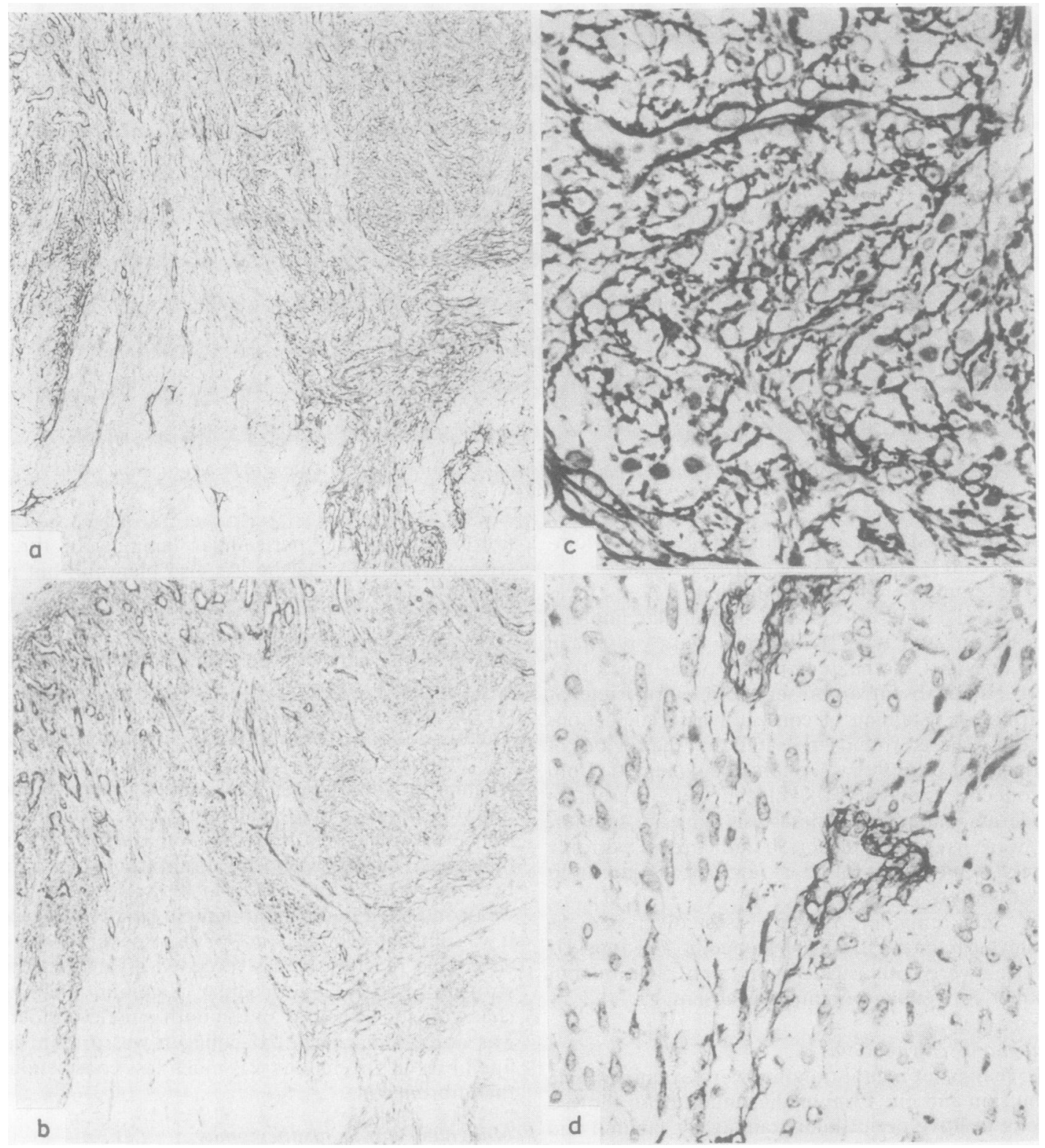

Fig. 4 Leiomyosarcoma of ileum stained for fibronectin $(a)$ and laminin $(b, c, d)$ showing coincident positive and negative areas. (c) Detail of positive area showing pericellular distribution. (d) Detail of negative area showing staining confined to blood vessels. Immunoperoxidase/haematoxylin. Original magnifications $\times 60(a, b) ; \times 600(c) ; \times 360(d)$.

dle cells but with occasional "epithelial lined" clefts within it. Fibronectin was plentiful in the stroma but was not obvious in cytoplasm of either spindle or "epithelial" cells. Laminin was seen lining some clefts but "epithelial" cell cytoplasm was negative. In spindle cell areas it was found only in vascular walls. Type III collagen was irregularly distributed in small to moderate amounts.

\section{Angiosarcoma}

Both fibronectin and laminin were abundant in this tumour. In some areas they were seen outlining well 


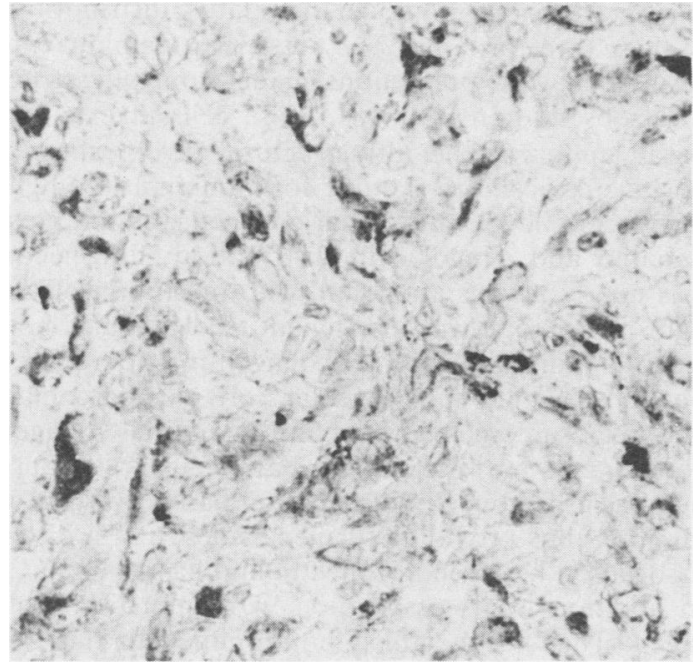

Fig. 5 Malignant fibrous histiocytoma stained for fibronectin. Immunoperoxidase/haematoxylin. $\times 600$. defined vascular channels; in others they were present beneath cells on the surfaces of papillae (Fig. 6 ). In some places they were irregularly disposed among tumour cells reproducing neither well defined vascular nor papillary structures. Type III collagen was present in much smaller amounts, although evident in fibrous septa and some papillary cores.

\section{Alveolar soft part sarcoma}

Both fibronectin and laminin were seen outlining tumour cell nests with a distribution corresponding to that of ultrastructurally detectable basal lamina (Fig. 7). Type III collagen was less regularly dispersed, appearing conspicuous around some but not all cell nests. It was also present in fibrous septa and in irregular bundles between individual cell groups.

Sarcomas (? type)

These were all grade III tumours in which the cell of origin could not be identified. All were negative for laminin except in blood vessel walls. Two had abun-
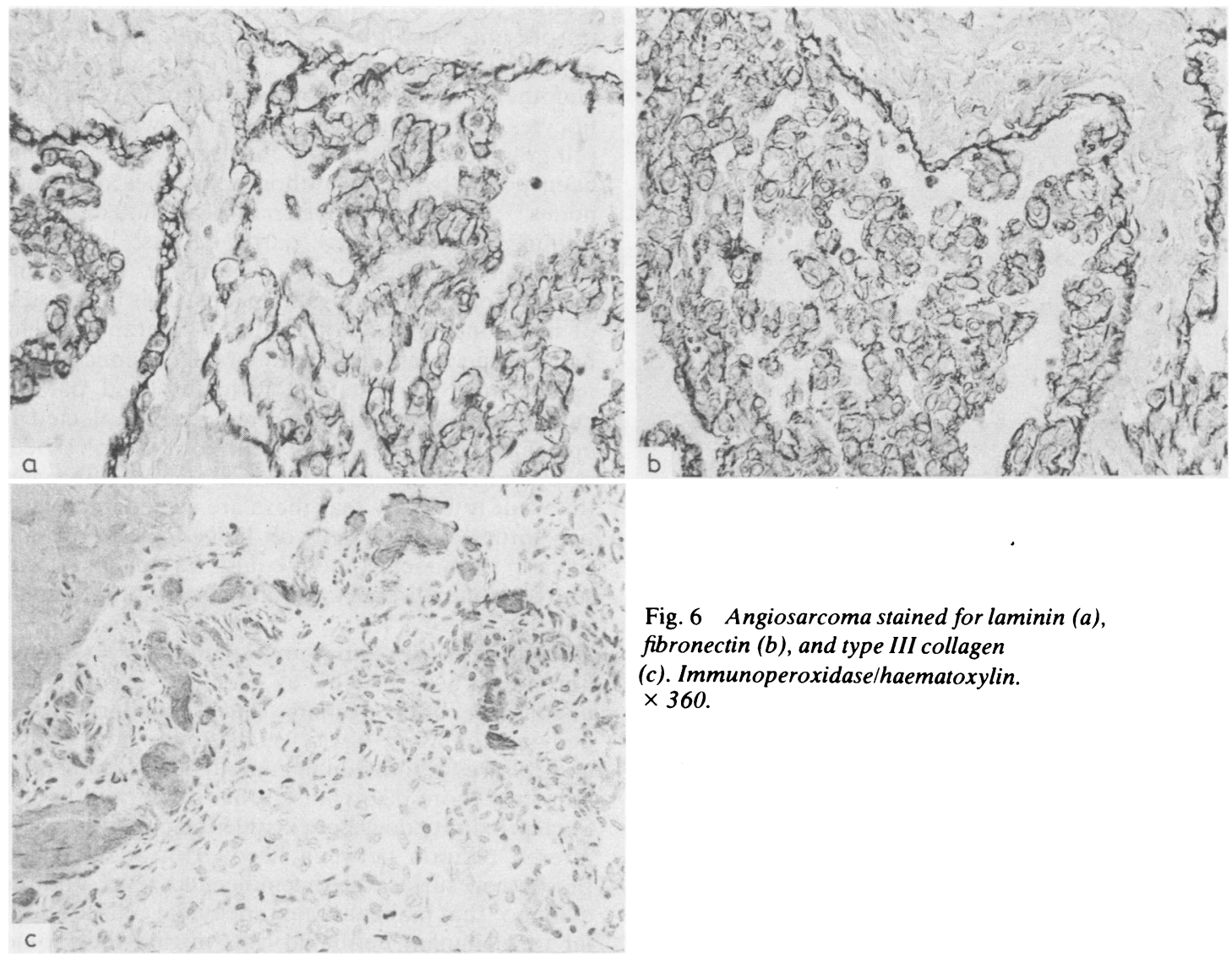

Fig. 6 Angiosarcoma stained for laminin (a), fibronectin (b), and type III collagen (c). Immunoperoxidase/haematoxylin. $\times 360$. 

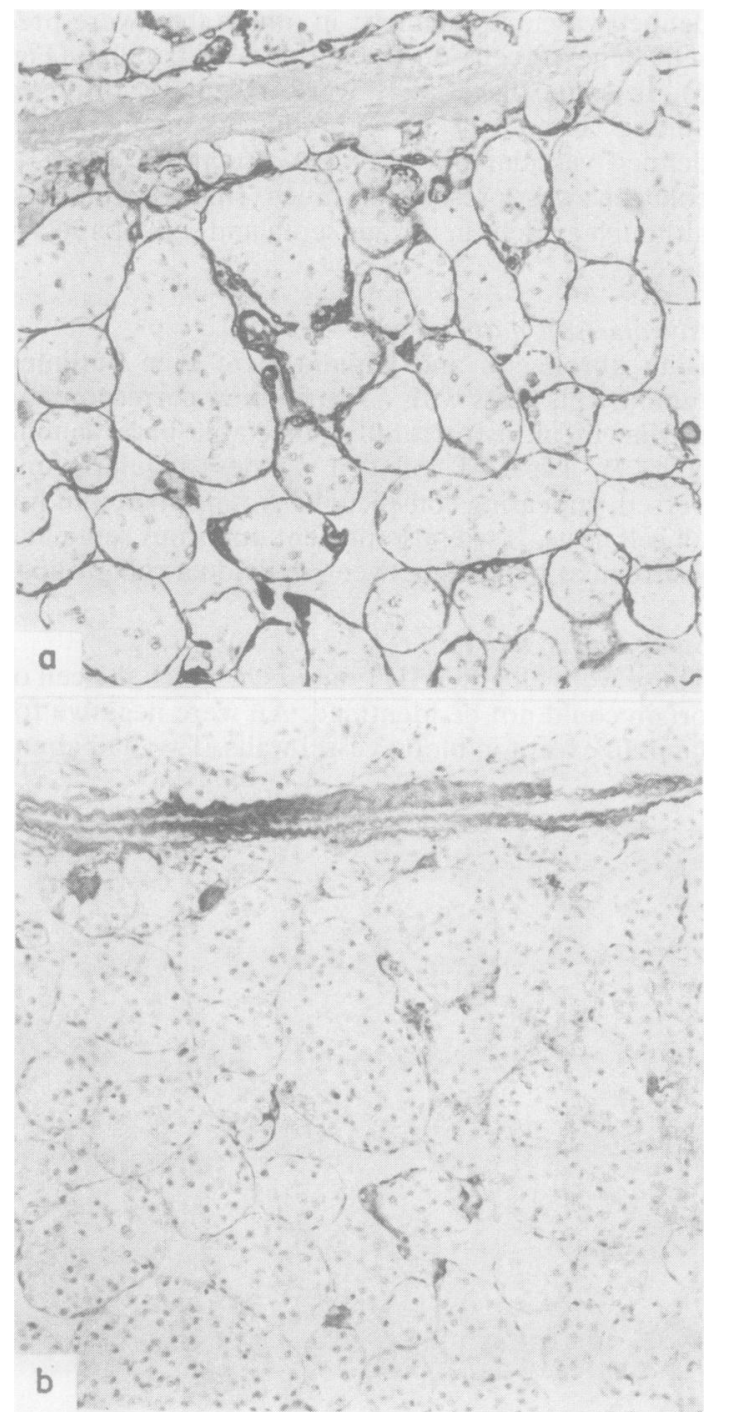

Fig. 7 Alveolar soft part sarcoma stained for laminin (a) and type III collagen (b). Immunoperoxidase/

haematoxylin. $\times 150$.

dant stromal fibronectin; the third was the only tumour in the whole series in which fibronectin was virtually absent. Type III collagen was present in varying quantities.

\section{Discussion}

This study has shown that although in a few tumours, in particular leiomyomas, the staining patterns of fibronectin, laminin, and type III collagen appear virtually identical, in the majority there are characteristic differences in the relative distributions of these three proteins. The presence of laminin corresponded with predictions made from ultrastructural observations - that is, those cells invested by basal lamina at the ultrastructural level ${ }^{26}$ showed positive pericellular staining for laminin at the light microscope level. Interstitial collagen was the most variable and irregular in distribution; fibronectin was nearly always abundant. The resolution of the light microscope was insufficient to distinguish between laminin and type III collagen in leiomyomas, but in schwannomas, alveolar soft part sarcomas, and angiosarcomas laminin and interstitial collagen components were clearly separable. In all these neoplasms fibronectin distribution paralleled that of laminin, thus providing further evidence of a direct association between fibronectin and basal lamina ${ }^{919}$ in addition to its association with interstitial collagen. That fibronectin is not confined to this site was illustrated by the many other tumours in which it was found in abundance in the absence of laminin. In some of these tumours, notably fibrous histiocytomas, type III collagen also appeared scanty relative to the large quantities of stainable fibronectin present. Such fibronectin might be tumour cell derived, but other possible sources include plasma, endothelial cells, non-neoplastic fibroblasts, and histiocytes. ${ }^{12}$ An incidental observation was that mast cell granules stain strongly for fibronectin. This has been noted by other authors in studies on lymph nodes, ${ }^{27}{ }^{28}$ although Moller $e t a l^{27}$ concluded that the staining was artefactual, partly because it had not been recorded previously. Forni et $a l^{29}$ found intracytoplasmic fibronectin in mast cells in a variety of situations but did not localise it to granules. This may be due to differing immunohistochemical technique, since they stained formalin fixed paraffin embedded tissue which had not been subjected to enzymatic digestion. Mast cell granules have been shown to release enzymes which degrade fibronectin,$^{30}$ but it is likely that these are stored in an inactive form. ${ }^{31}$ If mast cells do indeed synthesise and release fibronectin they could be an important source of the fibronectin found at sites of inflammation.

As found in previous investigations, ${ }^{1821}$ stromal fibronectin was usually as plentiful in malignant neoplasms, both primary and secondary, as in benign neoplasms. It was usually found both around and between individual tumour cells, but often appeared more disorganised than in normal tissues. Such proximity does not exclude the possibility of an altered relation between fibronectin and the neoplastic cell surface at the molecular level. Indirect evidence that malignant mesenchymal cells are similar to malignant epithelial cells in that they some- 
times but not always possess cell surface associated fibronectin, ${ }^{19}$ was given by the ileal leiomyosarcoma, in which fibronectin, laminin, and type III collagen appeared to be lost concomitantly from tumour cell peripheries, being present in some areas but not others (case 3 ). This appears analagous to the in vitro observation that fibronectin, laminin, and heparan sulphate proteoglycan may be lost simultaneously from the surfaces of rat kidney cells on viral transformation. ${ }^{14}$ In other parts of the tumour fibronectin and type III collagen were moderately plentiful while laminin was absent. These findings suggest that the normal organisation of the extracellular matrix is lost with decreasing differentiation and that although fibronectin and type III collagen may be present, their relations with tumour cells may differ from their relations with normal cells.

Loss of laminin in leiomyosarcomas may also be analogous to its loss in carcinomas, ${ }^{15} 16$ since it was present pericellularly in only six of 13 such neoplasms examined. It was found in both malignant neural tumours studied, but this may have been fortuitous, since neither of two malignant schwannomas examined by Miettinen et al were laminin positive. ${ }^{22}$ The presence of laminin appeared to correlate to some extent with conventional prognostic parameters, such as tumour size and mitotic index, but the correlation was by no means perfect. Two apparently "well differentiated" tumours had no pericellular laminin, and one leiomyosarcoma with a high mitotic rate and considerable cellular and nuclear pleomorphism had abundant laminin. It is of interest that similar findings have been reported for other mesenchymal cell markers. A recent study of the distribution of smooth muscle myosin in leiomyosarcomas showed it to be present in less than a third of those with spindle cell morphology and none of the epithelioid variety. ${ }^{32}$ In other respects there was no apparent correlation between the morphology of the tumours and positivity for myosin, although where electron micrographs were available there appeared to be some correspondence with the degree of smooth muscle differentiation seen ultrastructurally. It would be of interest to determine whether laminin positivity corresponds with positivity for myosin and other smooth muscle markers, and, more importantly, whether these markers provide a better indication of the degree of differentiation and prognosis of a tumour than conventional criteria. In the present study there was no evidence that laminin positivity was determined by site, since the six laminin positive leiomyosarcomas were from skin, ileum, retroperitoneum, broad ligament, and scrotum. Other studies have suggested that the location of a tumour may have some influence on its retention of smooth muscle characteristics-for example, gastric smooth muscle neoplasms lack stainable myosin,,$^{32}$ laminin, ${ }^{22}$ and ultrastucturally definable basal lamina. ${ }^{33}$ The observation that this applies to benign as well as malignant gastric neoplasms might argue against these features being of prognostic importance, in general.

Despite the finding that laminin is not invariably present around tumour cells of smooth muscle or neural derivation, this study has supported the previous suggestion that it may sometimes be of considerable diagnostic value. ${ }^{22}$ Laminin staining led to a revision of the original diagnosis in seven of the sixty cases examined. This emphasises the difficulty which may be experienced in diagnosing these neoplasms and the value of any diagnostic aid. While electron microscopy may provide a definitive answer in such cases it is more time consuming and may suffer from sampling error. That sampling may be relevant is indicated by the varying laminin positivity in case 3 (ileal leiomyosarcoma). Laminin staining may also be useful in the diagnosis of vascular tumours, since its delineation of vascular basal lamina is more specific than a reticulin stain. ${ }^{9}$ The diagnostic value of fibronectin staining is more doubtful. It is almost ubiquitous in tumour stroma and, although this investigation has confirmed its presence in synovial cells in giant cell synoviomas, ${ }^{21}$ it was no more conspicuous in the spindle cells of a synovial sarcoma than in fibroblasts in general. Similarly, it was prominent intracytoplasmically in only one of eight fibrohistiocytic lesions examined (excluding staining in mast cell granules). Interstitial collagen type III was found in the stroma of most tumours, although in varying quantities. It is noteworthy that it was as abundant in neoplasms of smooth muscle origin as in fibroblastic neoplasms and appeared consistently reduced only in fibrous histiocytomas. Further studies are required to determine whether quantity of interstitial collagen has any bearing on tumour behaviour.

Although immunohistochemical staining patterns for matrical proteins may not individually provide an immediate diagnostic solution, in combination they may be a valuable adjunct to conventional methods of histopathological assessment. These techniques give more specific information about the nature of a tumour matrix than routine connective tissue stains and it is hoped that their increased use may shed more light on the nature and behaviour of soft tissue neoplasms.

\footnotetext{
References

' Hay ED. Introductory remarks. In: Hay ED, ed. Cell biology of extracellular matrix. New York: Plenum Press, 1981:1-4.

${ }^{2}$ Timpl R, Rohde H, Gehron Robey P, Rennard SI, Foidart JM,
} 
Martin GR. Laminin - A glycoprotein from basement membranes. J Biol Chem 1979;254:9933-7.

${ }^{3}$ Foidart JM, Bere EW, Yaar M, et al. Distribution and immunoelectron microscopic localization of laminin, a noncollagenous basement membrane glycoprotein. Lab Invest 1980;42:336-42.

${ }^{4}$ Courtoy PJ, Timpl R, Farquhar MG. Comparative distribution of laminin, type IV collagen and fibronectin in the rat glomerulus. . J Histochem Cytochem 1982;30:874-86.

s Cohn RH, Banerjee SD, Bernfield MR. Basal lamina of embryonic salivary epithelia. Nature of glycosaminoglycan and organisation of extracellular materials. $J$ Cell Biol 1977;73:464-78.

- Gordon JR, Bernfield MR. The basal lamina of the postnatal mammary epithelium contains glycosaminoglycans in a precise ultrastructural organisation. Dev Biol 1980;74:118-35.

' Hascall VC, Hascall GK. Proteoglycans. In: Hay ED, ed. Cell biology of extracellular matrix. New York: Plenum Press, 1981:39-63

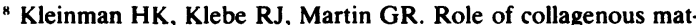
rices in the adhesion and growth of cells. J Cell Biol 1981;88:473-85.

' D' Ardenne AJ, Burns J, Sykes BC, Kirkpatrick P. Comparative distribution of fibronectin and type III collagen in normal human tissues. J Pathol 1983;141:55-69.

"Sanes JR, Cheney JM. Laminin, fibronectin and collagen in synaptic and extrasynaptic portions of muscle fibre basement membrane. J Cell Biol 1982;93:442-51.

" Boselli JM, Macarak EJ, Clark CC, Brownell AG, MartinezHernandez A. Fibronectin: Its relationship to basement membranes. I. Light microscopic studies. Coll Res 1981;5:391-404.

12 D' Ardenne AJ, McGee JO' D. Fibronectin in disease. J Pathol 1984; 142:235-51.

${ }^{13}$ Vaheri A, Mosher DF. High molecular weight, cell surfaceassociated glycoprotein (fibronectin) lost in malignant transformation. Biochim Biophys Acta 1978;516:1-25.

${ }^{14}$ Hayman EG, Oldberg A, Martin GR, Ruoslahti E. Codistribution of heparan sulphate proteoglycan, laminin, and fibronectin in the extracellular matrix of normal rat kidney cells and their co-ordinate absence in transformed cells. J Cell Biol 1982;94:28-35.

is Albrechtson R, Nielson M, Wewer U, Engvall E, Ruoslahti E. Basement membrane changes in breast cancer detected by immunohistochemical staining for laminin. Cancer Res 1981;41:5076-81.

${ }^{16}$ Birembaut P, Caron Y, Van Cauwenberger D, Foidart JM. Distribution of laminin, a basement membrane glycoprotein in epithelial proliferations. Collagen Related Research $1983 ; 3: 25-31$.

${ }^{17}$ Sugar J. Ultrastructural and histochemical changes during the development of cancer in various human organs. In: Tarin D, ed. Tissue interactions in carcinogenesis. London: Academic Press, 1972:127-59. is Stenman S, Vaheri A. Fibronectin in human solid tumours. Int $J$ Cancer 1981;27:427-35.

${ }^{14}$ D' Ardenne AJ, Burns J, Sykes BC, Bennett MK. Fibronectin and type III collagen in epithelial neoplasms of gastrointestinal tract and salivary gland. $J$ Clin Pathol 1983;36:756-63.

${ }^{20}$ Labat-Robert J, Birembaut P, Robert L, Adnet JJ. Modification of fibronectin distribution pattern in solid human tumours. Diagnostic Histopathology 1981;4:299-306.

21 Du Boulay CEH. Demonstration of fibronectin in soft tissue tumours using the immunoperoxidase technique. Diagnostic Histopathology 1982;5:283-9.

${ }^{22}$ Miettinen M, Foidart JM, Ekblom P. Immunohistochemical demonstration of laminin, the major glycoprotein of basement membranes as an aid in the diagnosis of soft tissue tumours. Am J.Clin Pathol 1983; 79:306-11.

${ }^{23}$ Enzinger FM, Weiss SW. Soft tissue tumours. St Louis: CV Mosby Company, 1983:9-10.

${ }^{24}$ Sinclair RA, Burns J, Dunnill MS. Immunoperoxidase staining of formalin-fixed, paraffin-embedded, human renal biopsies with a comparison of the peroxidase-anti-peroxidase (PAP) and indirect methods. J Clin Pathol 1981;34:859-65.

${ }^{25}$ Kirkpatrick P, D'Ardenne AJ. The effects of fixation and enzymatic digestion on the immunohistochemical demonstration of laminin and fibronectin in paraffin embedded tissue. $J$ Clin Pathol 1984;37:639-44.

${ }^{26}$ Ghadially FN. Diagnostic electron microscopy of tumours. London: Butterworths, 1980.

${ }^{27}$ Moller P, Achtstatter H, Butzengeiger M, Schule B. The distribution of fibronectin in lymph nodes infiltrated by Hodgkin's disease. Virchows Arch (Pathol Anat) 1983;400:319-29.

${ }^{2 k}$ Papadimitriou CS, Stephanaki-Nikou SN, Malamou-Mitsi VD. Comparative immunostaining of $\mathrm{T}$-associated plasma cells and other lymph node cells in paraffin sections. Virchows Archiv (Cell Pathol) 1983;43:31-6.

${ }^{24}$ Forni M, Klatt EC, Shaw ST, Taylor CR, Lukes RJ, Meyer PR. Immunohistochemical characterization of reactive and neoplastic mast cells. Am J Clin Pathol 1983;80:660-5.

30 Vartio T, Seppa H, Vaheri A. Susceptibility of soluble and matrix fibronectin to degradation by tissue proteinases, mast cell chymase and cathepsin G.J Biol Chem 1981;255:471-7.

${ }^{31}$ Yurt R, Austen KF. Purification of the rat cell chymase. J Exp Med 1977; 146: 1405-19.

${ }^{32}$ Donner L, Lanerolle P, Costa J. Immunoreactivity of paraffin embedded normal tissues and mesenchymal tumours for smooth muscle myosin. Am J Clin Pathol 1983;80:677-81.

${ }^{33}$ Welsh RA, Meyer AT. Ultrastructure of gastric leiomyoma. Arch Pathol 1969;87:71-81.

Requests for reprints to: Dr AJ d'Ardenne, Department of Pathology, Level 1, John Radcliffe Hospital, Headington, Oxford OX3 9DU, England. 